\title{
DEGRADABILIDADE IN SITU DE SILAGENS DE MILHETO EM OVINOS
}

\author{
Roberto Guimarães Júnior, ${ }^{1}$ Lúcio Carlos Gonçalves, ${ }^{2}$ Diogo Gonzaga Jayme, ${ }^{3}$ \\ Daniel Ananias de Assis Pires, ${ }^{4}$ José Avelino dos Santos Rodrigues ${ }^{5}$ e Thierry Ribeiro Tomich ${ }^{6}$ \\ 1. Pesquisador da Embrapa Cerrados, Planaltina, DF. E-mail: guimaraes@cpac.embrapa.br \\ 2. Escola de Veterinária da UFMG \\ 3. CEFET-Uberaba \\ 4. UNIMONTES - Janaúba \\ 5. Embrapa Milho e Sorgo \\ 6. Embrapa Pantanal.
}

\section{RESUMO}

O objetivo do estudo foi avaliar e comparar a degradabilidade ruminal in situ da matéria seca (MS), da proteína bruta (PB) e da fibra em detergente neutro (FDN) das silagens dos genótipos de milheto BRS-1501, NPM-1 e CMS-3, nos períodos de incubação de $6,12,24,48,72$ e 96 horas, em ovinos. O delineamento estatístico utilizado foi o de blocos ao acaso em arranjo de parcelas subdivididas, sendo as médias comparadas pelo teste SNK a 5\% de significância. As degradabilidades efetivas da matéria seca, nas taxas de passagem de $2,0 \% / \mathrm{h}, 5,0 \% / \mathrm{h}$ e $8,0 \% / \mathrm{h}$, foram de $48,5 \%$, $39,6 \%$ e $35,8 \%$ para a silagem do BRS- $1501,46,3 \%, 38,1 \%$ e $35,0 \%$, para a silagem do NPM-1, e $47,8 \%, 40,2 \%$ e $36,9 \%$, para a silagem do CMS-3, respectivamente. As maiores taxas de degradação $(2,08 \% / \mathrm{h})$, solubilidade $(74,4 \%)$ e degradabilidades efetivas da PB foram verificadas para a silagem do genótipo CMS-3. A degradabilidade potencial (A) da FDN mostrou-se igual à fração potencialmente degradável (B1) em todas as silagens, cujos valores foram 52,3\% (BRS-1501), 57,6\% (NPM-1) e $46,6 \%$ (CMS-3). A PB das silagens de milheto apresentou elevada solubilidade, e a silagem do genótipo CMS-3 mostrou melhor qualidade dessa fração. Observaram-se baixas degradabilidades da FDN para todas as silagens estudadas. Em conclusão, as silagens dos genótipos BRS-1501 e CMS-3 mostraram-se superiores à do NPM-1, por apresentarem maiores degradabilidades efetivas em todos os parâmetros avaliados.

PALAVRAS-CHAVES: Forragem, ruminantes, suplementação, valor nutritivo.

\section{ABSTRACT}

\section{IN SITU DEGRADABILITIES OF PEARL MILLET SILAGES IN SHEEP}

The objective of this study was to evaluate and to compare in situ dry matter (DM), crude protein (CP) and neutral detergent fiber (NDF) degradabilities of three pearl millet genotypes silages (BRS-1501, NPM-1 e CMS-3), incubated at 6, 12, 24, 48 and 96 hours in sheep. The experimental design was a randomized block in split plot arrangement, and the means compared by SNK test at $5 \%$ significance level. Values of effective degradability at $2.0 \% / \mathrm{h}$, $5.0 \% / \mathrm{h}$ and $8.0 \% / \mathrm{h}$ passage rates were: $48.5 \%, 39.6 \%$ and $35.8 \%$ for BRS- 1501 silage, $46.3 \%, 38.1 \%$ and $35.0 \%$ for NPM- 1 silage and $47.8 \%, 40.2 \%$ and $36.9 \%$ for CMS-3 silage, respectively. The highest degradation rate $(2.08 \% / \mathrm{h})$, solubility $(74.4 \%)$ and effective degradability of CP were observed for CMS-3. The potential degradability (A) of NDF was equal to the potentially degradable fraction (B1) in all silages, whose values were 52.3\% (BRS-1501), $57.6 \%$ (NPM-1) and 46.6\% (CMS-3). CP fraction of pearl millet silages presented high solubility and CMS-3 silage showed better quality of this fraction. Low NDF degradabilities were observed for all silages. According to the findings of this work, the BRS1501 and CMS-3 silages presented better nutritional value than the NPM-1 due to their highest effective degradabilities.

KEYWORDS: Nutritive value, roughage, ruminants, supplementation. 


\section{INTRODUÇÃO}

O milheto é uma forrageira de clima tropical de ciclo anual com grande potencial para utilização na dieta de ruminantes. Por se tratar de uma cultura que se desenvolve bem em condições de baixa precipitação pluviométrica, tem sido utilizada estrategicamente para produção de silagem em período de safrinha e em regiões com problemas de veranico ou seca. No Brasil, o milheto ainda é pouco estudado na forma de silagem, no entanto, alguns trabalhos (ALMEIDA et al., 1993; GUIMARÃES Jr., 2003; AMARAL et al., 2008) têm demonstrado que essa cultura, além de produtiva, origina silagens de valor nutritivo adequado, podendo ser indicada como opção para suplementação volumosa.

$\mathrm{Na}$ determinação do valor nutritivo de uma forragem, além de sua composição química, aspectos relacionados à extensão da digestão potencial e à taxa de fermentação são de grande relevância, uma vez que esses parâmetros estão diretamente envolvidos no controle do consumo voluntário (THIAGO, 1994), que, por sua vez, se relaciona com o desempenho animal. Por meio da técnica in situ, é possível estimar parâmetros relacionados à cinética de degradação de um alimento e de suas frações, em função de períodos de incubação no rúmen. Tratase de um método cujos resultados apresentam alta correlação com os obtidos em experimentos in vivo, é preciso, simples e rápido para determinar a qualidade de uma forragem. Por isso, tem sido de grande utilidade na avaliação de alimentos para ruminantes (ØRSKOV et al., 1980).

O conhecimento da degradabilidade in situ dos componentes nutricionais de diferentes genótipos de milheto é determinante na avaliação dessa forrageira na forma de silagem. Além de fornecer subsídios para utilização racional do alimento em dietas de ruminantes, contribui para o programa de melhoramento genético da cultura no sentido de selecionar e indicar materiais de melhor valor nutritivo para produção de silagem.

Com este trabalho objetivou-se avaliar e comparar a degradabilidade ruminal in situ da matéria seca (MS), da proteína bruta (PB) e da fibra em detergente neutro (FDN) das silagens de milheto BRS-1501, NPM-1 e CMS-3 em ovinos.

\section{MATERIAL E MÉTODOS}

O experimento foi realizado no Departamento de Zootecnia da Escola de Veterinária da Universidade Federal de Minas Gerais (UFMG), em Belo Horizonte. Utilizaram-se quatro ovinos, canulados no rúmen, castrados, com peso médio de $35 \mathrm{~kg}$ e idade entre 20 e 28 meses. A dieta dos animais foi composta por feno de Coast-cross (Cynodon spp.) à vontade e 300 gramas de concentrado comercial com teores de $20 \%$ de proteína bruta e $82,5 \%$ de nutrientes digestíveis totais (NDT). Administraram-se a água e mistura mineral comercial ad libitum.

Os genótipos de milheto avaliados foram o BRS-1501, NPM-1, e o CMS-3. O BRS-1501 é uma variedade lançada pela Embrapa Milho e Sorgo, de polinização aberta, originada por seleção massal de uma população americana. O NPM-1 (Nebraska Population Millet) é uma população de polinização aberta oriunda do programa de melhoramento da Universidade do Nebraska, USA, e o CMS-3 é uma população de polinização aberta do programa de melhoramento da Embrapa Milho e Sorgo.

As variedades de milheto foram plantadas no campo experimental da Embrapa Milho e Sorgo, localizada a $19^{\circ} 28^{\prime}$ de latitude sul $44^{\circ} 15^{\prime}$ ' de longitude oeste de Greenwich a 732 metros de altitude, no município de Sete Lagoas, MG. A adubação de plantio foi equivalente a $350 \mathrm{~kg} / \mathrm{ha}$ de $8-28-16$ (NPK) e a de cobertura a $100 \mathrm{~kg} / \mathrm{ha}$ de ureia, de acordo com as exigências da cultura.

Cem dias após o plantio, as plantas foram cortadas, manualmente, rente ao solo e reduzidas ao tamanho de partícula de aproximadamente $2,5 \mathrm{~cm}$ em picadeira estacionária. Em seguida, foram ensiladas, sob pisoteio, em tambores metálicos com capacidade para $200 \mathrm{~kg}$, revestidos internamente com lona de polietileno e dotados de tampa. Após sessenta dias de fermentação, procedeu-se à abertura dos silos, e as silagens foram amostradas, de maneira uniforme, no terço inicial, médio e final de cada tambor, formando uma amostra composta por genótipo. Da amostra composta, uma subamostra foi retirada, pré-seca em estufa de ventilação forçada a $65^{\circ} \mathrm{C}$ por 72 horas, e após moagem em tamanho de partícula de $1 \mathrm{~mm}$, utilizada para determinação dos teores de matéria seca (MS) (AOAC, 1995) e de proteína bruta (PB). Para 
tanto, multiplicou-se o teor de nitrogênio obtido pelo método de combustão de Dumas em analisador Leco ${ }^{\circledR}$ FP-528 por 6,25 . Os componentes da parede celular fibra em detergente neutro (FDN), fibra em detergente ácido (FDA), celulose, hemicelulose e lignina foram determinados segundo VAN SOEST et al. (1991), em aparelho ANKOM ${ }^{200}$ Fiber Analyser. Utilizou-se outra subamostra para extração da parte líquida ("suco") da silagem em prensa hidráulica Carver, sendo determinados os valores de $\mathrm{pH}$ em potenciômetro de Beckman Expandomatic SS-2 e nitrogênio amoniacal em percentagem do nitrogênio total $\left(\mathrm{NH}_{3} / \mathrm{NT}\right)$ (AOAC, 1995) (Tabela 1).

TABELA 1. Teores de matéria seca (MS), proteína bruta (PB), fibra em detergente neutro (FDN), fibra em detergente ácido (FDA), celulose, hemicelulose, lignina, expressos na base seca, $\mathrm{pH}$ e nitrogênio amoniacal em relação ao nitrogênio total $\left(\mathrm{NH}_{3} /\right.$ NT) das silagens de três genótipos de milheto

\begin{tabular}{lccc}
\hline & \multicolumn{3}{c}{ Genótipos } \\
\hline Parâmetros & BRS-1501 & NPM-1 & CMS-3 \\
\hline MS (\%) & 21,28 & 22,72 & 20,99 \\
PB (\%) & 11,83 & 10,73 & 11,45 \\
FDN (\%) & 70,54 & 71,22 & 71,02 \\
FDA (\%) & 37,70 & 39,71 & 39,37 \\
Celulose (\%) & 35,78 & 37,06 & 37,4 \\
Hemiceluloses (\%) & 32,84 & 31,51 & 31,65 \\
Lignina (\%) & 1,92 & 2,65 & 1,97 \\
pH & 3,79 & 3,71 & 3,75 \\
$\mathrm{NH}_{3}$ (NT (\%) & 11,97 & 8,86 & 9,25 \\
\hline
\end{tabular}

As amostras compostas utilizadas para determinação da degradabilidade in situ foram pré-secas em estufa de ventilação forçada a $65^{\circ} \mathrm{C}$ por 72 horas e, posteriormente, moídas em moinho com peneira de crivos de $5 \mathrm{~mm}$. Utilizaram-se sacos de náilon com porosidade de 50 micras para incubação. Preencheu-se cada saco com cerca $5 \mathrm{~g}$ de silagem, sendo incubado no rúmen por $6,12,24,48,72$ e 96 horas. A relação média de amostra por área superficial do saco foi de $17,5 \mathrm{mg} / \mathrm{cm}^{2}$. Incubaram-se as amostras no rúmen, em triplicata, por período de avaliação. Lavaram-se os sacos de incubação retirados do rúmen após os períodos de incubação em água corrente até que esta se mostrasse límpida. Para determinação da fração solúvel (tempo 0), procedeu-se ao mesmo procedimento, porém sem prévia incubação das amostras no rúmen. Após a lavagem, os sacos foram secos em estufa de ventilação forçada a ar por 72 horas a 65 ${ }^{\circ} \mathrm{C}$ e, posteriormente, pesados para determinação do desaparecimento da matéria seca (MS). Realizou-se a moagem dos resíduos de incubação em moinho com peneira de $1 \mathrm{~mm}$, sendo utilizados para determinação dos teores de MS, proteína bruta (PB) e fibra em detergente neutro (FDN), conforme descrito anteriormente. Os teores dessas frações nas amostras das forrageiras e nos resíduos de incubação, juntamente com os pesos dos materiais incubados e de seus resíduos, foram utilizados para os cálculos do desaparecimento das respectivas frações.

As condições do ambiente ruminal foram avaliadas pela determinação dos teores de $\mathrm{pH}$ e nitrogênio amoniacal (N-NH3) no líquido ruminal dos carneiros aos 30 minutos, 1, 2, 3, 5, 7 e 9 horas após o fornecimento da refeição, no primeiro e terceiro dia do período experimental.

Ajustaram-se os dados de desaparecimento dos componentes nutricionais por regressão não linear por meio do seguinte modelo proposto por SAMPAIO (1988): $\mathrm{p}=\mathrm{A}-\mathrm{B} \mathrm{e}^{-\mathrm{ct}}$, em que: $\mathrm{p}=$ porcentagem de degradação após um tempo (t) de incubação no rúmen; $\mathrm{A}$ $=$ degradabilidade potencial; $\mathrm{B}=$ parâmetro sem valor biológico; $\mathrm{c}=$ taxa de degradação da fração potencialmente degradável (B1). Calculou-se a fração B1 pela subtração da fração solúvel (S) da degradabilidade potencial $(\mathrm{A}-\mathrm{S})$.

As degradabilidades efetivas (DE) foram calculadas utilizando-se o seguinte modelo proposto por ØRSKOV \& McDONALD (1979):

$\mathrm{DE}=\mathrm{S}+[(\mathrm{B} 1 * \mathrm{c}) /(\mathrm{c}+\mathrm{K})]$, em que: $\mathrm{K}=$ taxa fracional de passagem dos sólidos no rúmen. $\mathrm{E}$ os demais parâmetros foram os mesmos descritos anteriormente. Os valores de $\mathrm{k}$ utilizados para o cálculo da DE foram de 2,0, 5,0 e $8,0 \% / \mathrm{h}$, de modo a caracterizar animais com baixo, médio e alto consumo, respectivamente (ARC, 1984).

Utilizou-se um delineamento experimental de blocos ao acaso, em esquema de parcelas subdivididas, em que os animais representaram os blocos, as silagens as parcelas e os tempos de incubação as subparcelas, 
conforme o seguinte modelo estatístico:

Yijk $=\mu+B i+E j+B E i j+T k+E T j k+$ eijk; em que: $\mathrm{Bi}=$ efeito do bloco i, i = 1, 2, 3, 4; Ej = efeito do genótipo $\mathrm{j}, \mathrm{j}=1,2,3$; BEij = efeito da interação bloco $v s$ genótipo (erro a); $\mathrm{Tk}=$ efeito do tempo de fermentação; $k, k=6,12,24,48,72,96$; Etjk = efeito da interação genótipo $v s$ tempo de fermentação; eijk $=$ erro tipo $b$.

Realizaram-se a análise de variância e as equações de regressão para os desaparecimentos dos componentes nutricionais por meio do programa Sistema para Análises Estatísticas e Genéticas (SAEG 8.0) (RIBEIRO JÚNIOR, 2001). As médias foram comparadas empregando-se o teste Student-Newman-Keuls (SNK) a 5\% de significância.

\section{RESULTADOS E DISCUSSÃO}

\section{Parâmetros ruminais}

Na Tabela 2 são descritos os valores de $\mathrm{pH}$ e nitrogênio amoniacal em $\mathrm{mg} \%$ do líquido ruminal dos animais experimentais.

TABELA 2. Valores de pH e concentrações médias de nitrogênio amoniacal ( $\mathrm{N}_{-} \mathrm{NH}_{3}$ em $\left.\mathrm{mg} \%\right)$ no líquido ruminal colhido em diferentes períodos após o fornecimento da refeição

\begin{tabular}{lcc}
\hline Tempo & $\mathrm{pH}$ & $\mathrm{NH}_{3}(\mathrm{mg} \%)$ \\
\hline 30 min. $^{1}$ & 6,43 & 6,83 \\
1 hora & 6,62 & 15,56 \\
2 horas & 6,57 & 14,80 \\
3 horas & 6,50 & 12,16 \\
5 horas & 6,42 & 8,81 \\
7 horas & 6,35 & 6,04 \\
9 horas & 6,40 & 5,95 \\
Média & 6,47 & 10,02 \\
\hline
\end{tabular}

${ }^{1}$ Minutos

O valor médio de $\mathrm{pH}$ foi de 6,47 , variando de 6,35 após 7 horas a 6,62 após 1 hora do fornecimento da dieta. Esses valores encontram-se numa faixa que permite um bom desenvolvimento microbiano. Segundo HOBSON \& STEWARD (1997), valores de $\mathrm{pH}$ entre 6,0 e 7,0 permitem a presença de todos os componentes da biomassa microbiana no rúmen (bactérias, principalmente as celulolíticas, protozoários e fungos) e ótima ação das enzimas microbianas (LINDBERG, 1985). Os teores médios de nitrogênio amoniacal oscilaram de $5,95 \mathrm{mg} \%$ após nove horas de fornecimento da dieta até $15,56 \mathrm{mg} \%$ uma hora após a refeição. O valor médio obtido foi de $10,02 \mathrm{mg} \%$, possibilitando uma adequada fermentação microbiana no rúmen. Segundo VAN SOEST (1994), a concentração mínima para garantir um processo fermentativo ruminal adequado situa-se por volta de $10 \mathrm{mg} \%$. Já SATTER \& SLYTER (1974) concluíram que 5,0 mg amônia por $100 \mathrm{~mL}$ de fluido ruminal são suficientes para o máximo crescimento microbiano.

Portanto, com base nos valores de $\mathrm{pH}$ e nitrogênio amoniacal observados no líquido ruminal dos animais utilizados no presente ensaio, pode-se inferir que as condições ruminais não foram limitantes à fermentação dos substratos avaliados.

Degradabilidade da matéria seca (MS)

Conforme observado na Tabela 3, as silagens avaliadas não diferiram $(\mathrm{P}>0,05)$ quanto à degradabilidade da MS até o período 24 horas de incubação. Após 48 horas, a degradabilidade da MS da silagem do genótipo BRS-1501 foi superior $(\mathrm{P}<0,05)$ à verificada para a silagem do NPM-1. No entanto, não diferiu significativamente da silagem do CMS-3. Nos períodos de 72 e 96 horas ocorreu uma mudança no comportamento da resposta, em que a silagem do genótipo CMS-3 passou a ser estatisticamente diferente à do BRS-1501, porém semelhante $(\mathrm{P}>0,05)$ à silagem do NPM-1, que não apresentou diferença em relação à do BRS-1501. Essa inversão pode ter sido causada em função das diferenças na estrutura da parede celular dos genótipos avaliados, principalmente na celulose. Isto porque, com o avanço do processo de degradação, as proporções dos carboidratos degradáveis (mono e dissacarídeos, pectina, hemiceluloses não lignificadas) diminuem e a sua relação com a celulose também, deixando-a menos cristalina (degradável) (GALLAGHER et al., 1989).

$\mathrm{O}$ efeito do período de fermentação em horas (x) sobre o desaparecimento da matéria seca (DMS) das silagens de milheto foi descrito pelas seguintes 
equações de regressão:

DMS (\%) BRS-1501 = -0,0035 $\mathrm{x}^{2}+0,6788 \mathrm{x}+29,979$ $\left(\mathrm{R}^{2}=0,97, \mathrm{P}<0,001\right)$

DMS (\%) NPM-1 = -0,0021 $x^{2}+0,5043 x+32,185\left(R^{2}\right.$ $=0,96, \mathrm{P}<0,001)$

DMS (\%) CMS-3 = -0,0031 $\mathrm{x}^{2}+0,5848 \mathrm{x}+32,165\left(\mathrm{R}^{2}\right.$ $=0,96, \mathrm{P}<0,001)$.

Os elevados coeficientes de determinação $\left(\mathrm{R}^{2}\right)$ demonstram que o modelo quadrático se ajustou adequadamente às curvas de degradação, evidenciando diferenças significativas ao longo dos períodos de fermentação $(\mathrm{P}<0,001)$.

TABELA 3. Desaparecimento médio (\%) da matéria seca de silagens de três genótipos de milheto em função dos tempos de incubação

\begin{tabular}{ccccc}
\hline \multicolumn{5}{c}{ Genótipos } \\
\hline Horários & BRS-1501 & NPM-1 & CMS-3 & Média \\
\hline 06 & $32,3^{\mathrm{A}}$ & $34,1^{\mathrm{A}}$ & $34,1^{\mathrm{A}}$ & 33,5 \\
12 & $38,7^{\mathrm{A}}$ & $38,8^{\mathrm{A}}$ & $39,6^{\mathrm{A}}$ & 39,0 \\
24 & $45,7^{\mathrm{A}}$ & $43,7^{\mathrm{A}}$ & $46,2^{\mathrm{A}}$ & 45,2 \\
48 & $53,7^{\mathrm{A}}$ & $50,6^{\mathrm{B}}$ & $51,6^{\mathrm{AB}}$ & 52,0 \\
72 & $60,1^{\mathrm{A}}$ & $57,6^{\mathrm{AB}}$ & $58,3^{\mathrm{B}}$ & 58,7 \\
96 & $63,2^{\mathrm{A}}$ & $60,8^{\mathrm{AB}}$ & $59,9^{\mathrm{B}}$ & 61,3 \\
\hline
\end{tabular}

Médias nas linhas seguidas por letras iguais não diferem pelo teste SNK $(\mathrm{P}>0,05) . \mathrm{CV}=3,47 \%$.

AMARAL (2003), avaliando silagens de três genótipos de milheto confeccionadas em duas idades de corte (70 e 90 dias), observou que em todos os materiais houve tendência de maiores valores de desaparecimento da matéria seca próximos às 48 horas de incubação, embora, ao longo do tempo, ainda estivesse ocorrendo degradação do material. Os valores médios de degradabilidades da MS das silagens de milheto nos períodos de 6 e 24 horas de fermentação foram similares aos obtidos por CARNEIRO et al. (2002) para silagens de sorgo $(35,3 \%, 42,8 \%)$ e de girassol $(30,3 \%, 43,9 \%)$. No entanto, comparando com o mesmo trabalho, as silagens de milheto apresentaram menores degradabilidades nos períodos de 48, 72 e 96 horas, verificando-se degradabilidades de $63,0 \%$, $75,4 \%, 84,6 \%$ para silagem de sorgo, e, $62,3 \%, 65,8 \%$, $66,4 \%$ para silagem de girassol, respectivamente.

Os parâmetros de degradação ruminal das sila- gens encontram-se na Tabela 4. A maior degradabilidade potencial (A) foi obtida para a silagem do genótipo NPM-1, sendo seguida pelas silagens dos genótipos BRS-1501 e CMS-3. Quanto às concentrações das frações solúveis (S), as silagens avaliadas apresentaram valores variando de $26,2 \%$ para o BRS- 1501 a $28,5 \%$ para o CMS-3. Para as frações degradáveis (B1), as silagem do BRS-1501 e do NPM-1 apresentaram valores próximos e maiores que a silagem do CMS-3. Com relação às taxas de degradação (c), maiores valores foram observados para os genótipos CMS-3 e BRS-1501. A silagem do genótipo NPM-1 apresentou uma baixa taxa de degradação $(1,58 \% / \mathrm{h})$, indicando que esse material necessita de mais tempo dentro do rúmen para que o seu potencial máximo de degradação seja atingido.

TABELA 4. Degradabilidade potencial (A), fração solúvel (S), fração potencialmente degradável (B1), taxa de degradação (c) e degradabilidades efetivas (DE), nas taxas de passagem 2,0\%, 5,0\% e $8,0 \% / \mathrm{h}$, da matéria seca de silagens de milheto

\begin{tabular}{lcccc}
\hline \multicolumn{5}{c}{ Genótipos } \\
\hline Parâmetros & BRS-1501 & NPM-1 & CMS-3 & Média \\
\hline A (\%) & 66,4 & 69,2 & 62,5 & 66,0 \\
S (\%) & 26,2 & 28,2 & 28,5 & 27,6 \\
B1 (\%) & 40,2 & 41,0 & 34,0 & 38,4 \\
c (\%/h) & 2,50 & 1,58 & 2,62 & 2,2 \\
DE 2,0\%/h (\%) & 48,5 & 46,3 & 47,8 & 47,5 \\
DE 5,0\%/h (\%) & 39,6 & 38,1 & 40,2 & 39,3 \\
DE 8,0\%/h (\%) & 35,8 & 35,0 & 36,9 & 35,9 \\
R & 0,98 & 0,96 & 0,96 & \\
\hline
\end{tabular}

Segundo BORGES (1997), as forragens mais digestíveis apresentam valores altos de "A", mas necessitam também de altos valores de "c", para que alcancem o potencial máximo de degradação em menor tempo. Para SAMPAIO (1988), os parâmetros A e c são os principais na qualificação de uma forragem. Um elevado valor de " $\mathrm{A}$ " indica um material muito degradável, ao passo que maior valor de "c" implica menor tempo para o desaparecimento da fração potencialmente degradável, sendo que forragens de boa qualidade devem apresentar taxas de degradação superiores a $2 \% / \mathrm{h}$. No presente ensaio, isso foi verificado somente para as silagens dos genótipos BRS-1501 e CMS-3. 
AMARAL (2003), avaliando a degradabilidade ruminal da matéria seca das silagens de três genótipos de milheto (BRS-1501, BN-1 e Comum) em duas idades de corte (70 e 90 dias), verificou valores maiores para taxas de degradação $(3,3 \%$ a 3,6\%/hora), menores para fração solúvel $(10,88 \%$ a $15,53 \%)$ e valores similares para fração degradável (39,32\% a 41,42\%), quando comparados aos teores médios obtidos no presente experimento. Já SARTI et al. (2005) verificaram, para silagem de milho confeccionada com aproximadamente 90 dias de idade, $79,1 \%$ para a fração A, 39,2\% para a fração S, 42,7\% para a fração B1 e 3\%h de taxa de degradação.

As degradabilidades efetivas (DE) para as taxas de passagem de $2,0 \% / \mathrm{h}, 5,0 \% / \mathrm{h}$ e $8,0 \% / \mathrm{h}$ foram de $48,5 \%, 39,6 \%$ e $35,8 \%$ para o BRS- $1501,46,3 \%$, $38,1 \%$ e $35,0 \%$ para o NPM- 1 e $47,8 \%, 40,2 \%$ e $36,9 \%$ para o CMS-3. Os valores de DE obtidos para taxa de passagem de $5 \% / \mathrm{h}$, característica de animais de nível médio de produção (ARC, 1984), foram superiores aos obtidos por AMARAL (2003) para silagens de milheto confeccionadas aos $70(29,85 \%)$ e $90(26,26 \%)$ dias de idade da cultura. Teores superiores de DE foram verificados por CARNEIRO et al. (2002), cujas degradabilidades efetivas foram de $62,3 \%$ para silagem de milho, 57,5\% para silagem sorgo e 55,1\% para silagem de girassol para a mesma taxa de passagem. Para a mesma taxa de passagem, valores mais elevados foram obtidos por PEREIRA (2003) em estudo de silagens de girassol ensiladas aos 100 (76,48\%), 107 (73,59\%), $114(70,48 \%)$ e $121(68,16 \%)$ dias. Esses resultados sugerem um melhor valor nutritivo dessas silagens quando comparadas às silagens de milheto avaliadas. As diferenças observadas entre silagens de milheto e de outras culturas podem ser atribuídas a diversos fatores, como cultura e variedades avaliadas, manejo de corte para ensilagem, condições de clima e de solo onde os materiais foram cultivados, manejo no estabelecimento, dentre outros. Tais fontes de variação podem alterar significativamente as proporções dos nutrientes nas plantas e, por consequência, os parâmetros de cinética de fermentação ruminal e degradabilidades efetivas.

Degradabilidade da proteína bruta (PB)

Quanto aos valores de desaparecimento médio da proteína bruta (Tabela 5), a silagem do genótipo CMS-3 foi a que apresentou maiores valores $(\mathrm{P}<0,05)$ nos períodos de 6 e 12 horas. A silagem do genótipo BRS-1501, por sua vez, apresentou valores superiores $(\mathrm{P}<0,05)$ à do NPM-1 nesses mesmos períodos. Às 24 e 48 horas, as silagens dos genótipos CMS-3 e BRS1501 apresentaram valores semelhantes $(\mathrm{P}>0,05)$ e maiores do que os verificados para a silagem do NPM-1 $(\mathrm{P}<0,05)$. Nos períodos finais de fermentação (72 e 96 horas), a silagem do genótipo BRS-1501 apresentou maiores valores de desaparecimento médio da $\mathrm{PB}$, a silagem do NPM -1 os menores e a do CMS-3 valores intermediários $(\mathrm{P}<0,05)$. $\mathrm{O}$ desaparecimento médio da PB das silagens de milheto às 96 horas foi próximo ao obtido por CAMPOS et al. (2003a) em estudo de silagens de quatro genótipos de sorgo, cujo valor foi $79,4 \%$.

TABELA 5. Desaparecimento médio (\%) da proteína bruta das silagens de três genótipos de milheto em função dos tempos de incubação

\begin{tabular}{ccccc}
\hline \multicolumn{5}{c}{ Genótipos } \\
\hline Horários & BRS-1501 & NPM-1 & CMS-3 & Média \\
\hline 06 & $68,2^{\mathrm{B}}$ & $66,1^{\mathrm{C}}$ & $69,9^{\mathrm{A}}$ & 68,1 \\
12 & $71,0^{\mathrm{B}}$ & $68,8^{\mathrm{C}}$ & $72,8^{\mathrm{A}}$ & 70,9 \\
24 & $71,0^{\mathrm{A}}$ & $69,8^{\mathrm{B}}$ & $73,5^{\mathrm{A}}$ & 71,4 \\
48 & $74,8^{\mathrm{A}}$ & $71,0^{\mathrm{B}}$ & $74,7^{\mathrm{A}}$ & 73,5 \\
72 & $78,5^{\mathrm{A}}$ & $74,5^{\mathrm{C}}$ & $77,8^{\mathrm{B}}$ & 76,9 \\
96 & $79,7^{\mathrm{A}}$ & $75,1^{\mathrm{C}}$ & $78,6^{\mathrm{B}}$ & 77,8 \\
\hline
\end{tabular}

Médias nas linhas seguidas por letras iguais não diferem pelo teste SNK $(\mathrm{P}>0,05) . \mathrm{CV}=1,26 \%$.

O efeito do período de fermentação em horas (x) sobre o desaparecimento da proteína bruta (DPB) das silagens de milheto foi descrito pelas seguintes equações de regressão:

DPB (\%) BRS-1501 = - 0,0008 $x^{2}+0,1994 x+67,898$ $\left(\mathrm{R}^{2}=0,93, \mathrm{P}<0,001\right)$

DPB (\%) NPM-1 = - 0,0006 $x^{2}+0,1513 x+66,1\left(R^{2}\right.$ $=0,84, \mathrm{P}<0,001)$

DPB $(\%)$ CMS-3 = - 0,0009 $x^{2}+0,1698 x+69,741\left(R^{2}\right.$ $=0,85, \mathrm{P}<0,001)$.

As equações polinomiais de segunda ordem descreveram adequadamente as curvas de degradação da PB, sendo verificadas diferenças significativas $(\mathrm{P}<0,001)$ ao longo dos períodos de fermentação.

Os parâmetros de cinética da degradação da 
PB são demonstrados na Tabela 6. O maior potencial de degradação da PB foi observado para a silagem do genótipo BRS-1501, sendo seguida pelo CMS-3 e NPM-1. Isso não foi verificado para as as concetrações da fração solúvel da PB e taxas de degradação, em que o CMS-3 se destacou entre os demais, apresentando valores de $74,4 \%$ e $2,08 \% / \mathrm{h}$, respectivamente. Esse resultado mostra que a fração proteica da silagem do genótipo CMS-3 é mais rapidamente disponibilizada para o animal, quando comparada às demais silagens. Com relação às frações potencialmente degradáveis, 0 BRS-1501 se destacou, com valor de $15,1 \%$, comparado com o NPM-1 (10,0\%) e CMS-3 (5,2\%).

TABELA 6. Degradabilidade potencial (A), fração solúvel (S), fração potencialmente degradável (B1), taxa de degradação (c) e degradabilidades efetivas (DE), nas taxas de passagem $2,0 \% \mathrm{~h}$, $5,0 \%$ h e $8,0 \% / \mathrm{h}$, da proteína bruta das silagens de três genótipos de milheto

\begin{tabular}{lcccc}
\hline \multicolumn{5}{c}{ Genótipos } \\
\hline Parâmetros & BRS-1501 & NPM-1 & CMS-3 & Média \\
\hline A (\%) & 83,9 & 78,0 & 79,6 & 80,5 \\
S (\%) & 68,8 & 68,0 & 74,4 & 70,4 \\
B1 (\%) & 15,1 & 10,0 & 5,2 & 10,1 \\
c (\%/h) & 1,42 & 1,52 & 2,08 & 1,7 \\
DE 2,0\%/h (\%) & 75,1 & 72,3 & 77,1 & 74,8 \\
DE 5,0\%/h (\%) & 72,3 & 70,3 & 75,9 & 72,8 \\
DE 8,0\%/h (\%) & 71,1 & 69,6 & 75,5 & 72,1 \\
R 2 & 0,94 & 0,84 & 0,85 & \\
\hline
\end{tabular}

PEREIRA (2003), em avaliação das silagens de girassol colhidas em quatro diferentes épocas de corte $(100,107,114$ e 121 dias após o plantio), obtiveram valores de "A" variando entre $87,0 \%$ e $89,3 \%$ e "c" de 6\%/h. Já TOMICH et al. (2004), estudando a degradabilidade da proteína bruta para o sorgo, capimsudão e capim-elefante Napier, obteve potenciais de degradação da $\mathrm{PB}$ variando entre $87,4 \%$ a $96,5 \%$ e taxas de degradação da proteína entre $1,46 \%$ e $5,55 \%$. GIMENES et al. (2006) verificaram potenciais de degradação da PB variando de $74,15 \%$ a $78,81 \%$ e taxas de degradação dessa fração entre $1,73 \%$ a $3,01 \%$, estudando silagens de milho confeccionadas com inoculantes bacteriano e/ou enzimático. Os valores de "B1" e "S" para as silagens de milheto avaliadas no presente experimento foram inversos, quando comparados com os experimentos de PEREIRA (2003) e TOMICH et al. (2004), cujos valores da fração degradável foram sempre menores do que a fração solúvel, em função da menor solubilidade da PB.

No caso das silagens de milheto, a alta solubilidade da fração proteica das silagens demonstra que grande parte desse nutriente é disponibilizada rapidamente para os animais. De acordo com o NRC (2001), a sincronização nas disponibilidades de nitrogênio e de energia favorece a utilização dos compostos nitrogenados da dieta e o maior suprimento de proteína microbiana pós-rúmen.

Portanto, em dietas de ruminantes em que a silagem de milheto constitui a base volumosa, a utilização de fontes de energia de rápida degradabilidade ruminal é indicada para maximizar o crescimento microbiano e favorecer a produtividade do animal. Tal informação é importante para os nutricionistas, quando da formulação de dietas ou misturas múltiplas em que a base volumosa é a silagem de milheto.

Quanto ao valor proteico, a silagem do genótipo CMS-3 foi superior às demais, pois apresentou maiores DE, influenciada pelo aumento da taxa de passagem, provavelmente, em função das maiores concentrações de fração solúvel e taxa de degradação desse material. Os valores de DE obtidos no presente experimento foram inferiores aos encontrados por PEREIRA (2003), em avaliação de silagens de girassol, e superiores aos determinados por TOMICH (2003), para as plantas de sorgo, capim-sudão, cana-de-açúcar e capim-elefante Napier, e aos valores encontrados por POSSETI et al. (2005), em avaliação das silagens de milho e girassol, considerando as mesmas taxas de passagem $(2, \% \mathrm{~h}$, $5 \% / \mathrm{h}, 8 \% \mathrm{~h})$.

Fibra em detergente neutro (FDN)

Os desaparecimentos médios da FDN das silagens dos genótipos de milheto são apresentados na Tabela 7. Durante os períodos de 6 e 12 horas de incubação, as silagens dos genótipos de milheto não diferiram entre si $(\mathrm{P}>0,05)$. No entanto, a partir de 24 horas, diferenças estatísticas foram verificadas. Nesse período, a silagem do NPM-1 foi a que apresentou menor degradabilidade da fração fibrosa, diferindo $(\mathrm{P}<0,05)$ do BRS-1501 e CMS-3, que foram seme- 
lhantes entre si $(\mathrm{P}>0,05)$. Às $48 \mathrm{~h}$, o valor de desaparecimento da FDN da silagem do genótipo NPM-1 igualou-se estatisticamente à do CMS-3, porém foi menor $(\mathrm{P}<0,05)$ que a do BRS-1501. A partir das 72 horas, a silagem do genótipo BRS-1501 apresentou as maiores degradabilidades da fração $\mathrm{FDN}(\mathrm{P}<0,05)$, quando comparada à do NPM-1 e CMS-3, que foram semelhantes estatisticamente entre si.

TABELA 7. Desaparecimento médio (\%) da fibra em detergente neutro das silagens de três genótipos de milheto em função dos tempos de incubação

\begin{tabular}{ccccc}
\hline \multicolumn{5}{c}{ Genótipos } \\
\hline Horários & BRS-1501 & NPM-1 & CMS-3 & Média \\
\hline 6 & $3,3^{\mathrm{A}}$ & $4,03^{\mathrm{A}}$ & $6,1^{\mathrm{A}}$ & 4,5 \\
12 & $11,6^{\mathrm{A}}$ & $8,9^{\mathrm{A}}$ & $12,1^{\mathrm{A}}$ & 10,9 \\
24 & $20,9^{\mathrm{A}}$ & $16,5^{\mathrm{B}}$ & $22,0^{\mathrm{A}}$ & 19,8 \\
48 & $33,3^{\mathrm{A}}$ & $27,0^{\mathrm{B}}$ & $30,1^{\mathrm{AB}}$ & 30,1 \\
72 & $41,9^{\mathrm{A}}$ & $36,5^{\mathrm{B}}$ & $38,9^{\mathrm{B}}$ & 39,1 \\
96 & $46,6^{\mathrm{A}}$ & $42,1^{\mathrm{B}}$ & $42,0^{\mathrm{B}}$ & 43,6 \\
\hline
\end{tabular}

Médias nas linhas seguidas por letras iguais não diferem pelo teste SNK $(\mathrm{P}>0,05) . \mathrm{CV}=9,93 \%$.

Os valores de desaparecimento da FDN em silagens de milho, sorgo e girassol no período de 96 horas foram, respectivamente, $81,5 \%, 73,2 \%$ e $40,7 \%$ (CARNEIRO et al., 2002). Os menores valores de degradabilidade da FDN em silagens de milheto podem ser justificados pelos teores elevados de FDN nas silagens, decorrentes da idade em que a planta foi colhida.

As avaliações de desaparecimento da FDN (DFDN) para um mesmo genótipo nos diferentes períodos de incubação $(\mathrm{x})$ podem ser descritas pelas seguintes equações de regressão:

DFDN (\%) BRS-1501 = - 0,0048 $x^{2}+0,9418 x-0,3087$ $\left(\mathrm{R}^{2}=0,98, \mathrm{P}<0,001\right)$

DFDN (\%) NPM-1 = - 0,0028 $\mathrm{x}^{2}+0,6967 \mathrm{x}+0,6215$ $\left(\mathrm{R}^{2}=0,96, \mathrm{P}<0,001\right)$

DFDN (\%) CMS-3 = - 0,0041 $\mathrm{x}^{2}+0,7977 \mathrm{x}+2,8272$ $\left(\mathrm{R}^{2}=0,96, \mathrm{P}<0,001\right)$.

Os elevados coeficientes de determinação $\left(\mathrm{R}^{2}\right)$ demonstram que o modelo quadrático descreveu adequadamente as curvas de degradação, evidenciando diferenças significativas ao longo dos períodos de fermentação $(\mathrm{P}<0,001)$.
Os potenciais de degradação, as taxas de degradação, frações degradáveis, os tempos de colonização e as degradabilidades efetivas da FDN são apresentados na Tabela 8. Os potenciais de degradação variaram de $57,6 \%$ para a silagem do genótipo NPM-1 a 46,6\% para a silagem do CMS-3. Quanto às taxas de degradação, as silagens dos genótipos BRS$1501(2,32 \% / h)$ e CMS-3 (2,39\%/h) apresentaram valores superiores ao verificado para silagem do NPM-1 $(1,38 \% / h)$. A menor taxa de degradação da silagem desse material pode ser atribuída a características físicas e estruturais da sua parede celular, capazes de dificultar o acesso microbiano a essa fração e, consequentemente, sua digestão (VAN SOEST, 1994). Os valores encontrados para o parâmetro A foram iguais aos verificados para a fração B1, uma vez que as frações FDN das silagens de milheto não apresentaram solubilidade em água.

TABELA 8. Degradabilidade potencial (A), fração potencialmente degradável (B1), taxa de degradação (c) e degradabilidades efetivas (DE), nas taxas de passagem $2,0 \% \mathrm{~h}, 5,0 \% \mathrm{~h}$ e $8,0 \% / \mathrm{h}$, da fibra em detergente neutro das silagens de três genótipos de milheto

\begin{tabular}{lcccc}
\hline \multicolumn{5}{c}{ Genótipos } \\
\hline Parâmetros & BRS-1501 & NPM-1 & CMS-3 & Média \\
\hline A (\%) & 52,3 & 57,6 & 46,6 & 52,2 \\
B1 (\%) & 52,3 & 57,6 & 46,6 & 52,2 \\
c (\%/h) & 2,32 & 1,38 & 2,39 & 2,0 \\
DE 2,0\%/h (\%) & 28,1 & 23,5 & 25,4 & 25,7 \\
DE 5,0\%/h (\%) & 16,6 & 12,5 & 15,1 & 14,7 \\
DE 8,0\%/h (\%) & 11,7 & 8,5 & 10,7 & 10,3 \\
$\mathrm{R}^{2}$ & 0,98 & 0,96 & 0,96 & \\
\hline
\end{tabular}

As degradabilidades efetivas para as silagens de milheto nas taxas de passagem de 2,5 e $8 \% / h$ foram baixas quando comparadas às verificadas em silagens de outras culturas. Os valores de DE para a silagem do BRS-1501 foram de $28,1 \%, 16,6 \%$ e $11,7 \% ; 25,4 \%$, $15,1 \%$ e $10,5 \%$ para o CMS-3, e $23,5 \%, 12,5 \%$ e $8,5 \%$ para o NPM-1, respectivamente, para as taxas de $2 \% \mathrm{~h}$, $5 \%$ h e $8 \%$ /hora. CAMPOS et al. (2003b) encontraram valores de DE variando de $30,3 \%$ a $39,1 \%$ para uma taxa de $2 \% / \mathrm{h}, 17,1 \%$ h a $29,4 \%$ para uma taxa de $5 \% / \mathrm{h}$ e de $12,0 \%$ h a $25,7 \% / \mathrm{h}$ para uma taxa de $8 \% / \mathrm{h}$ em silagens de quarto genótipos de sorgo. Os baixos va- 
lores para DE da FDN em todas as silagens avaliadas sugerem que a planta deve ser ensilada mais nova.

\section{CONCLUSÕES}

A proteína bruta das silagens de milheto apresentou elevada solubilidade e a fração fibrosa baixa degradabilidade.

A silagem do genótipo CMS-3 foi a de melhor qualidade da fração proteica.

Do ponto de vista nutricional, as silagens dos genótipos BRS-1501 e CMS-3 foram superiores à do NPM-1.

\section{REFERÊNCIAS}

AGRICULTURAL RESEARCH COUNCIL - ARC. The nutrient requirements of ruminant livestock. sppl. 1. Slough: Commonwealth Agricultural Bureaux, 1984. 45 p.

ALMEIDA, E. X.; TCACENCO, F. A.; STUCKER, H.; GROSS, C. D. Avaliação de cultivares de sorgo, milho, milheto e teosinto para o vale do Itajaí. Agropecuária Catarinense, v. 6, n. 3, p. 25-29, 1993.

AMARAL, P. N. C. Silagem e rolão de milheto em diferentes idades de corte. 2003. 78 f. Dissertação (Mestrado em Zootecnia) - Universidade Federal de Lavras, Lavras, MG, 2003.

AMARAL, P. N. C.; EVANGELISTA, A. R.; SALVADOR, F. M.; PINTO, J. C. Qualidade e valor nutritivo da silagem de três cultivares de milheto. Ciência Agrotécnica, v. 32, n. 2, p. 611$617,2008$.

ASSOCIATION OF OFFICIAL ANALYTICAL CHEMISTS AOAC. Official methods of analysis. 16. ed. Washington: AOAC, 1995. $2000 \mathrm{p}$.

BORGES, I. Influência da dieta na degradabilidade in situ do caroço de algodão integral, e do bagaço de cana-de-açúcar auto-hidrolisado, na dinâmica da fermentação ruminal e na cinética sangüínea de ovinos. 130 f. Tese (Doutorado em Ciência Animal) - UFMG, Belo Horizonte, 1997. Disponível em: <http:// servicos.capes.gov.br/capesdw/resumo.html?idtese $=199723320$ 01010042P5>

CAMPOS, W. E. ; SATURNINO, H. M.; SOUZA, B. M.; BORGES, I. Degradabilidade in situ da silagem de quatro genótipos doe sorgo com e sem tanino. I - Matéria seca e proteína bruta. Arquivo Brasileiro de Medicina Veterinária e Zootecnia, v. 55, n. 2, p. 209-215, 2003a.
CAMPOS, W. E. ; SATURNINO, H. M.; SOUZA, B. M.; GONÇALVES, L. C.; BORGES, I.; RODRIGUES, J. A. S.; CARVALHO, A. U.; FERREIRA, P. M. Degradabilidade in situ da silagem de quatro genótipos doe sorgo com e sem tanino. II - Fibra detergente neutro, fibra detergente ácido, hemicelulose e celulose. Arquivo Brasileiro de Medicina Veterinária e Zootecnia, v. 55, n. 4, p. 450-453, 2003 b.

CARNEIRO, J. C.; OLIVEIRA, E.; SILVA, J. O.; VIANA, A. C.; FERREIRA, J.; BORDONI, C. Avaliação da degradabilidade in situ da matéria seca e da fibra em detergente neutro de silagens de milho (Zea mays), sorgo (Sorghum bicolor) e girassol (Helianthus annuus) In: REUNIÃO ANUAL DA SOCIEDADE BRASILEIRADE ZOOTECNIA, 39., 2002, Recife. Anais... Recife: SBZ, 2002. CD-ROM. Disponível em: <http://www.sbz.org.br/cds/SBZ2002.rar>

GALLAGHER, I. M.; FRAZER, M. A.; EVANS, C. S.; ATKEY, P. T.; WOOD, D. A. Ultrastructural localization of lignocellulose degrading enzymes. In: LEWIS, N. G.; PAICE, M. G. (Ed.). Plant cell wall polymers: biogenesis and biodegradation. 1. ed. Washington: American Chemical Society, 1989. p. 426-453.

GIMENES, A. L. G.; MIZUBUTI, I. Y.; MOREIRA, F. B.; PEREIRA, E. S.; RIBEIRO, E. L. A.; MORI, R. M. Degradabilidade in situ de silagens de milho confeccionadas com inoculantes bacteriano e/ou enzimático. Acta Scientiarum Animal Sciences, v. 28, n. 1, p. 11-16, 2006.

GUIMARÃES Jr., R. Potencial forrageiro, perfil de fermentação e qualidade das silagens de três genótipos de milheto [Pennisetum glaucum (L). R. Br.]. 2003. 44 f. Dissertação (Mestrado em Zootecnia) - Escola de Veterinária, Universidade Federal de Minas Gerais, Belo Horizonte, MG, 2003. Disponível em: <http://servicos.capes. gov.br/capesdw/resumo.html?idtese $=200317232001010029$ P9>

HOBSON, P. N.; STEWART, C. S. The rumen microbial ecosystem. 1. ed. London: Blackie Academic and Professional, 1997. $340 \mathrm{p}$.

LINDBERG, J. E. Estimation of rumen degradability of feed proteins with the in sacco technique and various in vitro methods: a review. Acta Agriculturae Scandinavica, suppl. 25, p. 65-97, 1985.

NATIONAL RESEARCH COUNCIL - NRC. Nutrient requirements of dairy cattle. 7. ed. Washington: National Academy Press, 2001. 362 p.

ØRSKOV, E. R.; HOVELL, F. D. B.; MOULD, F. The use of the nylon bag technique for evaluation of feedstuffs. Tropical Animal Production, v. 5, p. 195-213, 1980.

ØRSKOV, E. R.; McDONALD, J. The estimation of protein degradability in the rumen from incubation measurements of feed in 
weighted according to rate of passage. Journal of Agricultural Science, v. 92, n. 2, p. 499-503, 1979.

PEREIRA, L. G. R. Potencial forrageiro da cultura do girassol (Helianthus annuus L.) para a produção de silagem. 2003, 134 f. Dissertação (Doutorado em Ciência Animal) - Belo Horizonte, Escola de Veterinária da UFMG, 2003. Disponível em: <http:// servicos.capes.gov.br/capesdw/resumo.html?idtese $=20031563$ 2001010042P5>

POSSETI, R. A.; FERRARI JR. E.; BUENO, M. S.; BIANCHINI, D.; LEINZ, F. F.; RODRIGUES, C. F. Parâmetros bromatológicos e fermentativos das silagens de milho e girassol. Ciência Rural, v. 35, n. 5 , p. 1185-1189, 2005.

RIBEIRO JÚNIOR, J. I. Análises estatísticas no SAEG. Viçosa: UFV, 2001. 301 p.

SAMPAIO, I. B. M. Experimental designs and modelling techniques in the study of roughage degradation in rumen and growth of ruminants. 1988. $214 \mathrm{f}$. Tese (Doutorado em Fisiologia) - Reading, Univesity of Reading, 1988. Disponível em: <http://servicos.capes.gov.br/capesdw/resumo.html?idtese= 19881832001010029P9>

SARTI, L. L.; JOBIM, C. C.; BRANCO, A. F.; JACOBS, F. Degradação ruminal da matéria seca, da proteína bruta e da fração fibra de silagens de milho e de capim-elefante. Ciência Animal Brasileira, v. 6, n. 1, p. 1-10, 2005.

SATTER, L. D.; SLYTER, L. L. Effect of ammonia concentration on rumen microbial protein production in vitro. British Journal of Nutrition, v. 32, n. 7, p. 199-205, 1974.

THIAGO, L. R. L. S. Utilização da técnica de degradabilidade in situ para avaliação de forragens e alimentos concentrados. In: SIMPÓSIO INTERNCIONAL DE PRODUÇÃO DE RUMINANTES, 1994, Maringá. Anais... Maringá: EDUEM, 1994. p. 89-93.

TOMICH, T. R.; RODRIGUES, J. A. S.; TOMICH, R. G. P.; GONÇALVES, L. C.; BORGES, I. Potencial forrageiro de híbridos de sorgo com capim-sudão. Arquivo Brasileiro de Medicina Veterinária e Zootecnia, Belo Horizonte, v. 56, n. 2, p. 258-263, 2004.

VAN SOEST, P. J. Nutritional ecology of the ruminant. 2. ed. Ithaca: Cornell University Press, 1994. 476 p.

VAN SOEST, P. J.; ROBERTSON, J. B.; LEWIS, B. A. Methods for dietary fiber, neutral detergent, and nonstarch polysaccharides in relation to animal nutrition. Journal of Dairy Science, v. 74, n. 10 , p. 3583-3597, 1991. 